\title{
Respuesta fisiológica al déficit hídrico in vitro y análisis proteómico preliminar en callos de cuatro cultivares de Allium cepa L. (cebolla)
}

\author{
Physiologic response to hydric déficit in vitro and \\ preliminary proteomic analysis in calli of four cultivars \\ of Allium cepa L. (Onion) \\ Ysabel Díaz V. ${ }^{1}$, Herbert O. Lazo R. ${ }^{1}$, Juan Pablo Portilla Ll. ${ }^{1}$, Luis A. Ponce-Soto ${ }^{2}$, \\ Sergio Marangoni ${ }^{2^{*}}$
}

\begin{abstract}
RESUMEN
La presente investigación tuvo por objetivo estudiar la respuesta fisiológica y proteómica al déficit hídrico in vitro inducido por el polietilen-glicol (PEG-8000) en callos de cuatro cultivares de cebolla, 'Sivan' y 'Americana' (rojas), 'Ica' y 'Ram' (amarillas). En todos los cultivares sin aclimatamiento (Sin-PEG) el porcentaje de sobrevivencia disminuyó conforme se incrementaron las concentraciones de PEG-8000; en contraste, en los callos con aclimatamiento (Con-PEG 10\% p/v) incrementó el porcentaje de sobrevivencia en 'Ica' y 'Sivan' y disminuyó en 'Americana' y 'Ram', en las más bajas concentraciones de PEG-8000. Los cultivares 'Ica' y 'Americana' presentaron su máximo porcentaje de sobrevivencia en el mayor tratamiento con PEG-8000 (40\%), 'Sivan' incrementó a 47\% y 'Ram' disminuyó a 22,8\% de sobrevivencia. El valor de $\mathrm{DHL}_{50}$ en los callos con-PEG se incrementó significativamente en 'Ica' (11,38\% de PEG-8000 p/v) y 'Sivan' (10,5\% de PEG-8000 p/v). La concentración de carbohidratos solubles totales disminuyó en 'Americana', en 'Sivan' e 'Ica' se incrementaron y en 'Ram' el incremento fue más del doble. La concentración de prolina se aumentó significativamente $(\mathrm{p}<0,05)$ en 'Ica', 'Sivan' y 'Americana', pero disminuyó en 'Ram'. Respecto al contenido de proteína soluble, éste aumentó significativamente $(\mathrm{p}<0,05)$ en los cuatro cultivares. El estudio proteómico preliminar muestra proteínas relacionadas con el crecimiento celular y enzimas relacionadas con la actividad ascorbato peroxidasa y superóxido dismutasa en 'Ica' y 'Sivan', capaces de aclimatarse al déficit hídrico, indicando un posible rol de estas proteínas en la tolerancia al déficit hídrico.
\end{abstract}

Palabras clave: estrés hídrico, cultivo de callos, aclimatamiento, agente osmótico, osmolitos.

\begin{abstract}
The objective of this investigation was study the physiologic and proteomic response to hydric deficit in vitro induced by $P E G$ 8000 , in calli of four cultivars of onion, 'Sivan' and 'Americana' (red), 'Ica' and 'Ram' (yellow). For all the cultivars without acclimatization treatment (without PEG) the survival percentage diminished in relation to increasing of concentration of PEG, whereas with acclimatization (10\% of PEG-8000) the survival percentage increased in 'Ica' and 'Sivan', and it diminished in 'Americana' and 'Ram' al lowest concentrations of PEG. 'Ica' and 'Americana' presented the highest percentage of survival at $40 \%$ of PEG, 'Sivan' increased to 47\%, and 'Ram' shown its lowest value (22.8\%). The value of DHL ${ }_{50}$ in calli with-PEG, increased significatively in 'Ica' $(11.38 \%$ PEG $w / v)$ and 'Sivan' $(10.5 \%$ de PEG $w / v)$. With-PEG, the content of carbohydrates diminished in 'Americana'. In 'Sivan' and 'Ica' the carbohydrates increased and in 'Ram' the increasing was twofold. The proline level increased in 'Ica', 'Sivan' and 'Americana'; but it diminished in 'Ram'. The concentration of soluble protein increased in all cultivars. The preliminary proteomic analysis shows proteins related with the growth cellular and enzymes related with the activity Ascorbate peroxidase and Superoxide dismutase in 'Ica' and 'Sivan' with capacity to acclimatization, indicating a possible role of these proteins in the tolerance to hydric deficit.
\end{abstract}

Key words: hydric stress, calli culture, acclimatization or hardiness, osmotic agency, compatible solutes.

\footnotetext{
Laboratorio de Fisiología y Biotecnología Vegetal, Universidad Nacional de San Agustín de Arequipa, Perú.

2 Laboratorio de Química de Proteínas, Instituto de Biología, Universidad Estadual de Campinas, SP- Brasil. E-mail: poncesoto@ pq.cnpq.br
}

Fecha de Recepción: 22 Junio, 2012.

Fecha de Aceptación: 12 Septiembre, 2012. 


\section{Introducción}

En términos globales, la sequía y el déficit hídrico limitan el crecimiento y la productividad de los cultivos, más que cualquier otro factor ambiental (Boyer, 1982). En el Perú, la Región Arequipa, de clima desértico por su baja humedad y escasa precipitación, es el principal productor de cebolla a nivel nacional con $31.260 \mathrm{~kg} / \mathrm{h}$ mensual en una superficie de 9.989 ha (Ministerio de Agricultura 2002). No obstante que el cultivo de cebolla se riega por gravedad, éste es sensible al déficit hídrico en la primera fase fenológica. La emergencia de la radícula es el estadio más sensible y solo puede progresar si el potencial hídrico del suelo es superior a $-1,1 \mathrm{MPa}$, bajo este valor se retrasa la emergencia hasta que la lluvia o el riego eleven el potencial hídrico, de lo contrario no prospera y muere (Whalley et al., 2001).

La adaptación de las plantas al déficit hídrico es dependiente de la capacidad de percepción y transducción de señal, expresión génica y producción de metabolitos que protejan y mantengan los componentes de la estructura celular (Shen y Wang, 2006). El estudio de los mecanismos de respuesta fisiológicos, bioquímicos y moleculares al déficit hídrico en condiciones de laboratorio hace uso del polietilénglicol (PEG-8000), un polímero de elevado peso molecular que simula las condiciones de estrés por déficit hídrico, al disminuir el potencial hídrico de las soluciones, sin penetrar en las células, siendo una herramienta útil en la selección de genotipos tolerantes (Hasegawa et al., 1984; Handa et al., 1986). Asimismo, el interés por comprender los mecanismos relacionados con este tipo de estrés ha dado lugar al empleo de técnicas de cultivo de tejidos vegetales que proporcionan material homogéneo, lo que permite en mayor grado dilucidar estos mecanismos (Tal, 1983). Existe evidencia contundente de que la respuesta de callos al déficit hídrico se asemeja a la de los tejidos intactos, así como a nivel de ápices meristemáticos, suspensiones celulares y protoplastos, sometidos a estrés hídrico y de congelamiento en los que se han evaluado los cambios metabólicos, enzimáticos y estructurales, tanto en plantas ornamentales como en cultivadas (Bhaskaran et al., 1985).

En el presente trabajo se utilizó la técnica del cultivo de tejidos vegetales en medio nutritivo de Dunstan y Short (1977) con diferentes concentraciones de PEG-8000, con el objetivo de estudiar la respuesta fisiológica y proteómica al déficit hídrico en callos de cuatro cultivares de cebolla, 'Sivan' y 'Americana' (rojas), 'Ica' y 'Ram' (amarillas), para lo cual se determinaron los cambios en la acumulación de solutos compatibles (carbohidratos solubles totales y prolina), en la concentración de proteínas solubles y en la expresión de proteínas, correlacionando dichos cambios con la capacidad de tolerancia a la sequía.

\section{Materiales y Métodos}

\section{Material biológico}

Se trabajó con callos cultivados in vitro de cuatro cultivares de cebolla (Allium cepa L.), 'Sivan' (roja), 'Americana' (roja), 'Ica' (amarilla) y 'Ram' (amarilla).

\section{Medio de cultivo}

El medio utilizado fue BDS (Dunstan y Short, 1977), suplementado con mioinositol (100mg/L), glicina $(2 \mathrm{mg} / \mathrm{L})$, tiamina $(10 \mathrm{mg} / \mathrm{L})$, piridoxina (1mg/L), ácido nicotínico (1mg/L), sacarosa $(30 \mathrm{~g} / \mathrm{L})$, BAP $(0,1 \mathrm{mg} / \mathrm{L}), 2,4-\mathrm{D}(2 \mathrm{mg} / \mathrm{L})$ y Phytagel (Sigma) $(3,5 \mathrm{~g} / \mathrm{l})$. El $\mathrm{pH}$ se ajustó a 5,5 con $\mathrm{HCl}(0,1 \mathrm{~N})$. Se distribuyeron $20 \mathrm{ml}$ de medio en frascos de vidrio de $100 \mathrm{ml}$, se taparon con papel aluminio y se autoclavaron a $15 \mathrm{lb}$ de presión y $121^{\circ} \mathrm{C}$ por 15 minutos.

\section{Obtención de callos}

Semillas de los cuatro cultivares fueron lavadas con agua y detergente líquido (Tide) por $10 \mathrm{~min}$, enjuagadas con agua destilada, desinfestadas con etanol $70 \%$ por 1 min e hipoclorito de $\mathrm{Na}$ al 1,6\% de cloro activo con dos gotas de Tween 20 por cada $100 \mathrm{ml}$ por $20 \mathrm{~min}$, agitando constantemente. Se enjuagaron tres veces con agua destilada estéril, dejando las semillas en el agua del último enjuague por $24 \mathrm{~h}$ a temperatura ambiente en la cámara de siembra. Se desechó el agua del último enjuague, y se repitió el proceso de desinfestación una vez más. Los embriones extraídos se cortaron por la mitad colocándose cuatro explantes por frasco. Se incubó en oscuridad a $18 \pm 2{ }^{\circ} \mathrm{C}$ y se repicó cada 20 días en un medio fresco por cuatro meses. A partir del segundo repique se colocó un callo por frasco de $50 \mathrm{ml}$ conteniendo $15 \mathrm{ml}$ de medio BDS. 


\section{Aclimatamiento de callos}

Cuatro callos de tres meses de edad, de cada cultivar, se colocaron sobre un puente de papel filtro Whatman $\mathrm{N}^{\circ} 3$ en un frasco con $20 \mathrm{ml}$ de medio líquido BDS. El medio BDS, de la mitad de los frascos, contenía PEG-8000 al 10\% (p/v) (aclimatamiento) y la otra mitad no contuvo PEG (sin aclimatamiento) (Bhaskaran et al., 1985). Se incubó en oscuridad a $18 \pm 2{ }^{\circ} \mathrm{C}$ por 15 días. Estos explantes fueron usados en las diferentes determinaciones.

\section{Determinación del porcentaje de supervivencia y tolerancia media al déficit hídrico $\left(\mathrm{DHL}_{50}\right)$}

Callos de $5 \mathrm{~mm}$ de diámetro de cada cultivar, con y sin aclimatamiento, fueron trasvasados a tubos de ensayo conteniendo $5 \mathrm{ml}$ de solución a las concentraciones de 0, 5, 10, 20 y 40\% de PEG-8000 (peso/volumen, diluido en medio BDS) cubriendo un rango de potencial hídrico de -0,2 MPa a -1,66 $\mathrm{MPa}$, por 24 horas (Whalley et al., 2001). Luego se lavaron tres veces con $5 \mathrm{ml}$ de agua desionizada estéril, dejándolos en el agua del último enjuague por 24 horas. El porcentaje de sobrevivencia se determinó con el test de viabilidad del trifeniltetrazolio (TTC, SIGMA), descrito por Towill y Mazur (1975). Los valores de las muestras control equivalen al 100\% de supervivencia, y la concentración de PEG-8000, capaz de producir un $50 \%$ de reducción de la viabilidad se considera la tolerancia media al déficit hídrico $\left(\mathrm{DHL}_{50}\right)$, previa transformación logarítmica de la curva según el test de Probit (Li, 1969).

\section{Determinación de solutos compatibles}

Los carbohidratos solubles totales y la prolina se determinaron según los métodos descritos por Steubing et al. (2002).

\section{Determinación de proteína soluble}

Se determinó según el método descrito por Steubin et al. (2002).

\section{Determinación del patrón de expresión de proteínas por electroforesis bidimensional (2D)}

Callos de los cuatro cultivares de 75 días de edad, con y sin aclimatamiento durante 24 horas, se trasvasaron a tubos Eppendorfs con $0,5 \mathrm{ml}$ de
$\mathrm{NaCl}$ al $15 \%$, para ser analizados posteriormente por electroforesis bidimensional (2D), evaluándose el pI y la masa molecular (Mm) aparente de proteínas, usando parámetros independientes para el cálculo de pI y Mm de los programas de análisis de imagen screen linear "grids" de pI y Mm (Westermeier, 2005). El análisis de imagen permitió identificar las proteínas reveladas con Coomassie blue, a través de una base de datos obtenida por Internet (http:// ca.expasy.org/tools/\#proteome).

\section{Diseño experimental}

Para el porcentaje de sobrevivencia se aplicó un Diseño Completo Randomizado (DCR) con arreglo trifactorial $4 \times 2 \times 5$, donde el primer factor son los cuatro cultivares de cebolla ('Sivan', 'Ram', 'Ica', 'Americana'), el segundo factor el tratamiento de aclimatamiento (10\% de PEG-8000) y sin aclimatamiento (0\% de PEG-8000) y el tercer factor las cinco diferentes concentraciones de PEG-8000 ( 0 , $5,10,20,40 \%$ p/v) empleadas. Se trabajó con cinco repeticiones, haciendo un total de 200 unidades experimentales, cada una de las cuales corresponde a un tubo de ensayo conteniendo un callo en 5 $\mathrm{ml}$ de medio líquido BDS con la correspondiente concentración de PEG-8000. Para la determinación de prolina, carbohidratos y proteína total, el diseño fue un DCR con un arreglo bifactorial $4 \times 2$, donde el primer factor son los cuatro cultivares de cebolla y el segundo factor el tratamiento con aclimatamiento y sin aclimatamiento, y cinco repeticiones por tratamiento, haciendo un total de 40 unidades experimentales. Los datos registrados se sometieron a un análisis de varianza (ANVA) y al test de especificidad de Tukey (Li, 1969).

\section{Resultados y Discusión}

\section{Porcentaje de sobrevivencia y $\mathrm{DHL}_{50}$}

La Figura 1, muestra que sin-PEG (sin aclimatamiento) disminuyó la sobrevivencia, siendo 'Ica' y 'Ram' más sensibles respecto a 'Sivan' y 'Americana'. A concentraciones de 5 y $10 \%(\mathrm{p} / \mathrm{v})$ de PEG, incrementó el porcentaje de sobrevivencia en callos con-PEG (con aclimatamiento) en 'Ica' (29,2 y $24,7 \%$, respectivamente) y 'Sivan' (45 y $58 \%$, respectivamente), y disminuyó en 'Americana' (5,7 y $6,1 \%$, respectivamente) y 'Ram' (30,9 y $20,5 \%$, respectivamente). A concentraciones mayores a $20 \%$ 


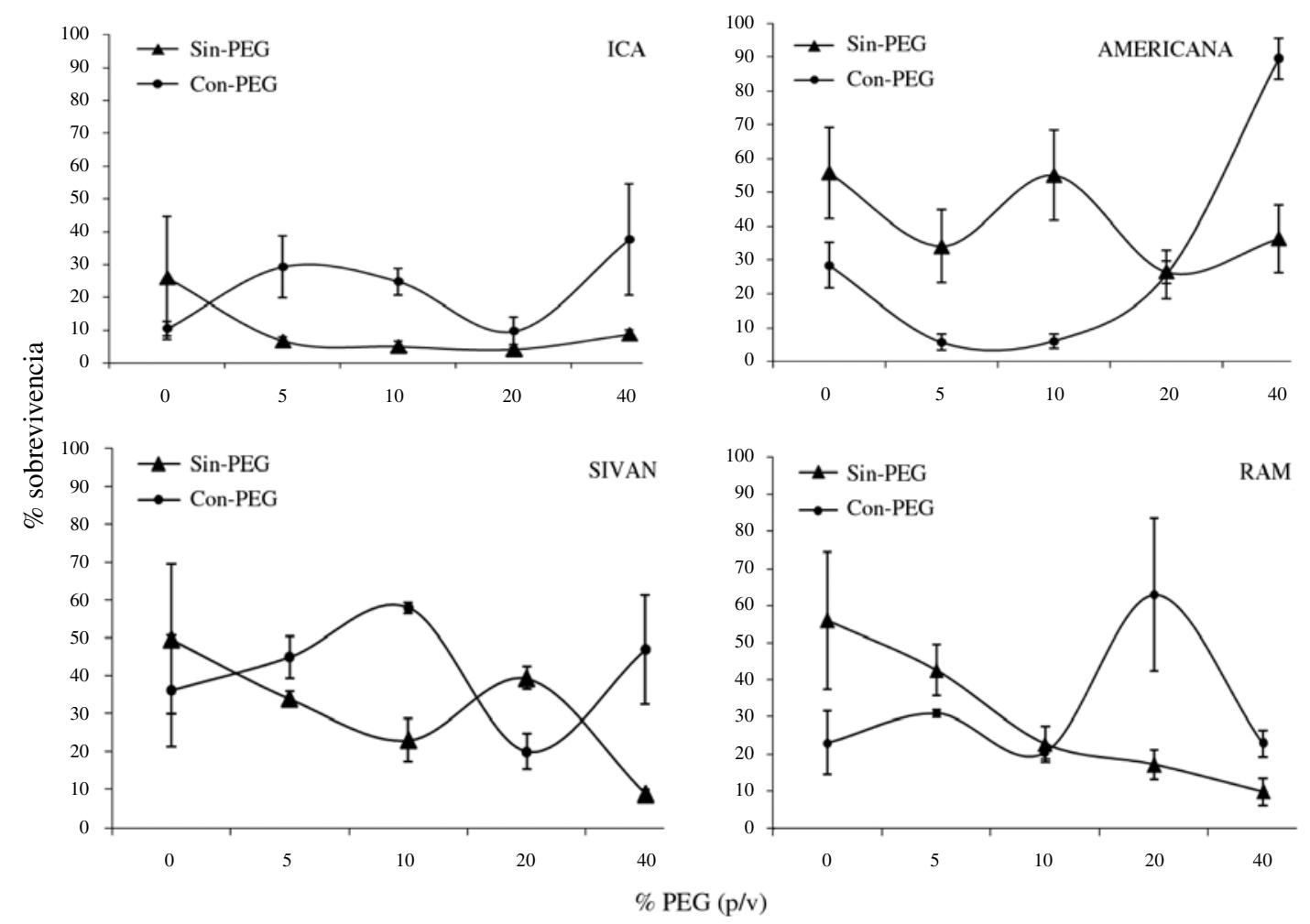

Figura 1. Porcentaje de sobrevivencia de callos de cuatro cultivares de Allium cepa L. con aclimatamiento y sin aclimatamiento frente a diferentes grados de déficit hídrico. Los valores son promedio de cinco repeticiones.

$(\mathrm{p} / \mathrm{v})$ de PEG, la sobrevivencia se incrementó en todos los cultivares, excepto en 'Ram'. A 40\% de PEG 'Ica' y 'Americana' presentaron su máximo porcentaje de sobrevivencia ( 37,6 y $89,6 \%$, respectivamente), en cambio ‘Sivan' incrementó a 47\% y ‘Ram' presentó uno de sus valores más bajos $(22,8 \%)$. Sin-PEG, todos los cultivares presentaron bajos valores de $\mathrm{DHL}_{50}$ (Figura 2), mientras que con-PEG se incrementó significativamente $(\mathrm{p}<0,05)$ en 'Ica' $(11,38 \%$ de PEG $\mathrm{p} / \mathrm{v})$ y 'Sivan' (10,5\% de PEG p/v). 'Ica' presentó el mayor valor de $\mathrm{DHL}_{50}$ con respecto a 'Ram' $(6,25 \%$ de PEG-8000 p/v). 'Americana' no mostró mayor variación en sus valores de $\mathrm{DHL}_{50}$.

El porcentaje sobrevivencia se basa en la capacidad de las células viables de los callos para reducir el trifeniltetrazolio, luego de ser expuestos a concentraciones crecientes de PEG-8000. Los genotipos con capacidad para aclimatarse (tolerantes), muestran mayor porcentaje de sobrevivencia, como se observó en 'Ica' y 'Sivan', lo que se correlaciona con el incremento en sus valores de $\mathrm{DHL}_{50}$, mientras que 'Americana' y 'Ram', no mostraron capacidad para aclimatarse (Figura 2).

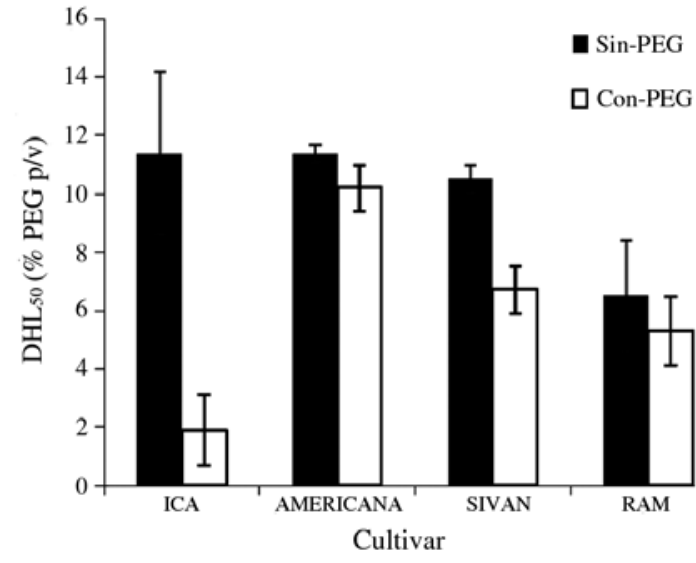

Figura 2. Valores de $\mathrm{DHL}_{50}$ en callos de cuatro cultivares de Allium cepa $\mathrm{L}$. con aclimatamiento y sin aclimatamiento a un déficit hídrico moderado. Los valores son promedio de cinco repeticiones.

\section{Solutos compatibles}

La Figura 3, muestra que 'Ram' y 'Americana' sin-PEG presentaron menor contenido de carbohidratos 
respecto a 'Sivan' e 'Ica'. Con-PEG, el nivel de carbohidratos en 'Americana' disminuyó significativamente (de 8,85 a 4,53 mg/gpf), en 'Sivan' e 'Ica' se incrementó (de 16,64 a 19,98 mg/gpf y 12,36 a $14,58 \mathrm{mg} / \mathrm{gpf}$, respectivamente), pero en 'Ram' el incremento fue más del doble (de 3,29 a 7,49 mg/gpf). Estas diferencias son inherentes al origen del cultivar, lo que se relacionaría con cambios en su metabolismo, como ha sido observado en el crecimiento de callos del género Populus (Tschaplinski et al., 1995). El nivel de prolina libre se incrementó significativamente $(\mathrm{p}<0,05)$ en los cultivares ConPEG menos en 'Ram' (disminuyó de 1,51 a 1,34 uM/gpf) (Figura 4). En 'Ica', 'Sivan' y 'Americana' (éste último que no se aclimató) el incremento fue de 1,62 a 2,53 uM/gpf; 1,35 a 1,94 uM/gpf y de 1,79 a 2,16 uM/gpf, respectivamente. La capacidad para aclimatarse se relaciona con altas concentraciones de osmolitos, cuyo propósito es retener agua y mantener el estado de turgencia. Los cultivares 'Ica' y 'Sivan' con capacidad para aclimatarse presentaron valores altos de carbohidratos solubles totales respecto a 'Americana' y 'Ram', sin capacidad para aclimatarse. Esta respuesta se relacionaría con la mayor sobrevivencia y crecimiento de los callos al ser expuestos al tratamiento con PEG, ya que mantendrían un gradiente de potencial hídrico favorable que permite el flujo de nutrientes, mantener la turgencia celular y proteger las membranas celulares de la deshidratación (Handa et al., 1986). No obstante, el incremento en más de dos veces la concentración de carbohidratos en 'Ram', luego del aclimatamiento (Figura 3) no sería suficiente para contrarrestar el déficit hídrico que redujo su capacidad de crecimiento, debido a que sus valores basales fueron muy bajos. Por otro lado, 'Americana', incapaz de aclimatarse, disminuyó su concentración de carbohidratos incrementando sus niveles de prolina (Figura 3), lo que explica su lento crecimiento y mayor capacidad de sobrevivencia (a $40 \%$ p/v de PEG) al destinar los carbohidratos para la formación de prolina, la cual estaría protegiendo las proteínas de membrana, como ha sido descrito en el caso del estrés hídrico, salino, baja y alta temperatura en diferentes especies (Handa et al., 1986; Claussen, 2005). En 'Ica' y 'Sivan' se presenta una correlación positiva entre la capacidad para aclimatarse y la acumulación de prolina luego del aclimatamiento (Figura 4). Esta acumulación se debería al alto contenido de carbohidratos que favorecen la vía biosintética en la que participa el ácido glutámico como precursor de la síntesis de prolina y/o a la inhibición de la oxidación de la prolina por las altas concentraciones de carbohidratos (Handa et al., 1986). En el caso de 'Americana', los azúcares se utilizarían en la síntesis de prolina y en 'Ram' por tener bajas concentraciones de carbohidratos se produciría una mayor oxidación de prolina y, por tanto, una menor concentración de este aminoácido, que se presenta como un posible marcador de déficit hídrico en esta especie, como se ha observado también en plantas de cebada (Singh et al., 1987), tomate (Claussen, 2005) y suspensiones celulares de tomate (Handa et al., 1986). Los resultados obtenidos son concordantes con lo observado en plantas de sorgo,

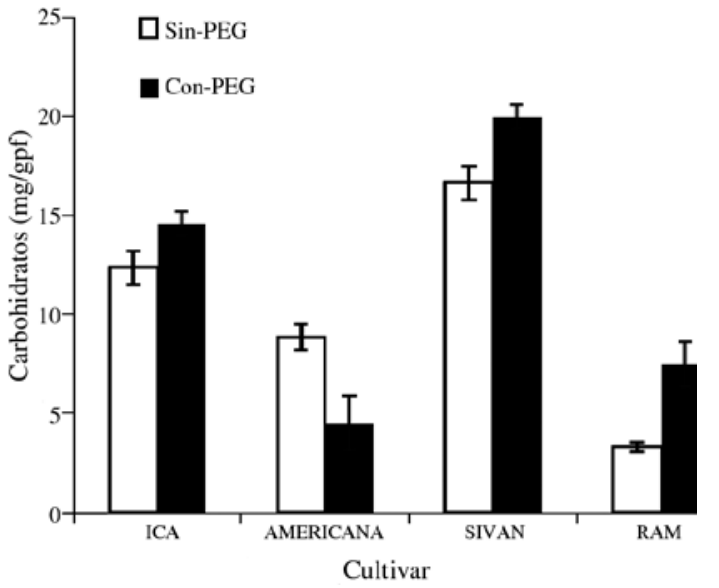

Figura 3. Contenido de carbohidratos solubles totales (mg/g.p.f.) de callos de cuatro cultivares de Allium cepa L., con aclimatamiento y sin aclimatamiento a un déficit hídrico moderado. Los valores son promedio de cinco repeticiones.

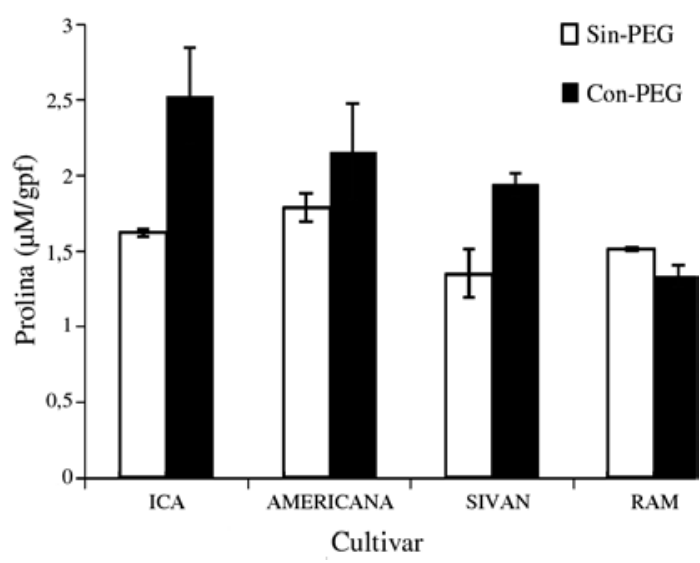

Figura 4. Contenido de prolina libre ( $\mu \mathrm{M} / \mathrm{g}$.p.f.) de callos de cuatro cultivares de Allium cepa L., con aclimatamiento y sin aclimatamiento a un déficit hídrico moderado. Los valores son promedio de cinco repeticiones. 
mijo (Kusaka et al., 2005), suspensiones celulares de tomate (Handa et al., 1986), callos de Citrus auriantum, Citrus sinensis, Sorghum bicolor L. y suspensiones celulares de Nicotiana tabacum var. Samsum, Licopersicon sculentum Mill. cv VFNTcherry, que mostraron capacidad de ajuste osmótico al crecer en medios con concentraciones crecientes de PEG-8000 al incrementar la concentración de solutos compatibles como carbohidratos, glicinabetaina y prolina (Bhaskaran et al., 1985; Handa et al., 1986). También se ha informado que cultivos de tejidos de tabaco y tomate (Hasegawa et al., 1984; Handa et al., 1986) presentaron acumulación de carbohidratos como respuesta al déficit hídrico provocado por PEG-4000 y PEG-6000, evidencia que corrobora la capacidad de tolerancia al déficit hídrico de 'Ica' y 'Sivan'.

\section{Proteína soluble}

Los niveles basales mayores se presentaron en las cebollas rojas ('Sivan' y 'Americana') y menores en las amarillas ('Ica' y 'Ram'), pero luego del aclimatamiento, la concentración de proteína soluble se incrementó significativamente $(\mathrm{p}<0,05)$ en los cuatro cultivares, mostrando un mayor incremento 'Ica' (de 78,48 a 253,12 mg/gpf), 'Ram' (de 107,22 a $277,29 \mathrm{mg} / \mathrm{gpf}$ ) y 'Americana' (de 180,88 a 309,55 $\mathrm{mg} / \mathrm{gpf})$, mientras que en 'Sivan' el incremento fue en menor cuantía (de 178,01 a 273,49 mg/gpf) (Figura 5). El incremento en el contenido de proteína soluble indica posiblemente un daño a nivel de proteínas estructurales de membrana, correlacionando

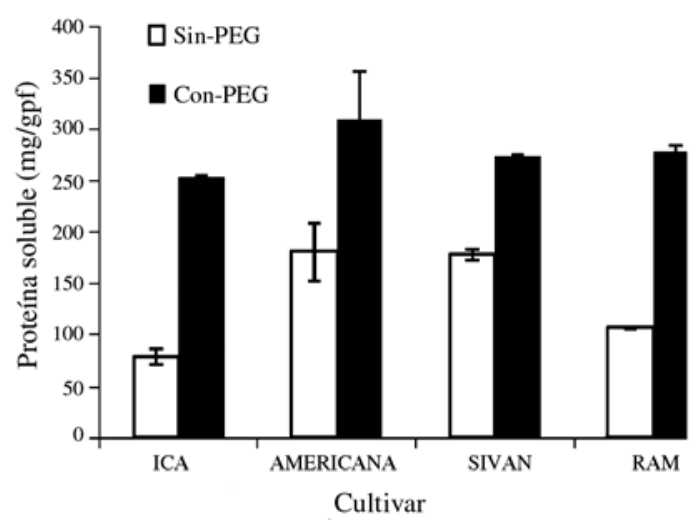

Figura 5. Contenido de proteína soluble (mg/gpf) en callos de cuatro cultivares de Allium cepa L., con aclimatación y sin aclimatación a un déficit hídrico moderado. Los valores son promedio de cinco repeticiones. el menor incremento con menor daño o síntesis de enzimas relacionadas con la síntesis de ABA y crecimiento celular (Ho y Sachs, 1989).

\section{Patrón de expresión de proteínas}

La Figura 6, muestra los spots de proteínas de los cultivares con aclimatamiento (con-PEG) y sin aclimatamiento (sin-PEG); los códigos de cada spot, como A101, corresponden al spot 1 localizado en el análisis de imagen del cultivar 'Americana'. Sin-PEG, en 'Americana', se expresan dos proteínas, A101 y A102, de distinta masa molecular y punto isoeléctrico; y con-PEG desaparece la proteína A101 (peroxidasa) y se mantiene la proteína NAP1, relacionada con chaperonas de histonas (H2A y H2B) y el ensamblamiento de la tubulina y ciclinas mitóticas (Dong et al., 2005; Li et al., 2004). En 'Ica', sin-PEG se muestran tres proteínas con actividad antioxidante (I101, I102, I103), una proteína reguladora relacionada con los niveles de la F-actina y formación de la placa celular (I104) y un fragmento de la proteína syntaxina asociada con el tráfico vesicular en la célula (I105) (Asada y Shibaoka, 1994); y con-PEG desaparecen las tres enzimas antioxidantes y el fragmento de la proteína syntaxina, apareciendo dos nuevas proteínas con actividad antioxidante (I106 y I107), manteniéndose la proteína PIR, relacionada con la formación de la placa celular (Li et al., 2004). En 'Ram', sin-PEG se presentan seis proteínas: dos con actividad geranilgeranil reductasa de distinta masa y pI relacionada con la biosíntesis del ABA (R101, R105), una syntaxina (R103), un fragmento de syntaxina de distinta masa molecular y pI (R106), una proteína precursora de la flagelina B2 (R102) y una enzima antioxidante (R104); y con-PEG desaparecen las proteínas R105 (geranilgeranil reductasa), R104 (ascorbato peroxidasa) y aparece una nueva enzima con actividad catalasa (R107). En 'Sivan', sin-PEG se expresan nueve proteínas: siete con actividad antioxidante (S101, S102, S103, S104, S105, S106, S108), una reductasa (S107) y otra perteneciente a un fragmento de la proteína syntaxina (S109); y con-PEG desaparecen cuatro proteínas con actividad peroxidasa (S102, S103, S104 y S105) y aparece una syntaxina de baja masa molecular y distinto pI (S110). El Cuadro 1 muestra la relación de las proteínas identificadas en el proteoma en base a los valores de $\mathrm{Mm}$ y pI, muchas de las cuales, que comparten una semejante 

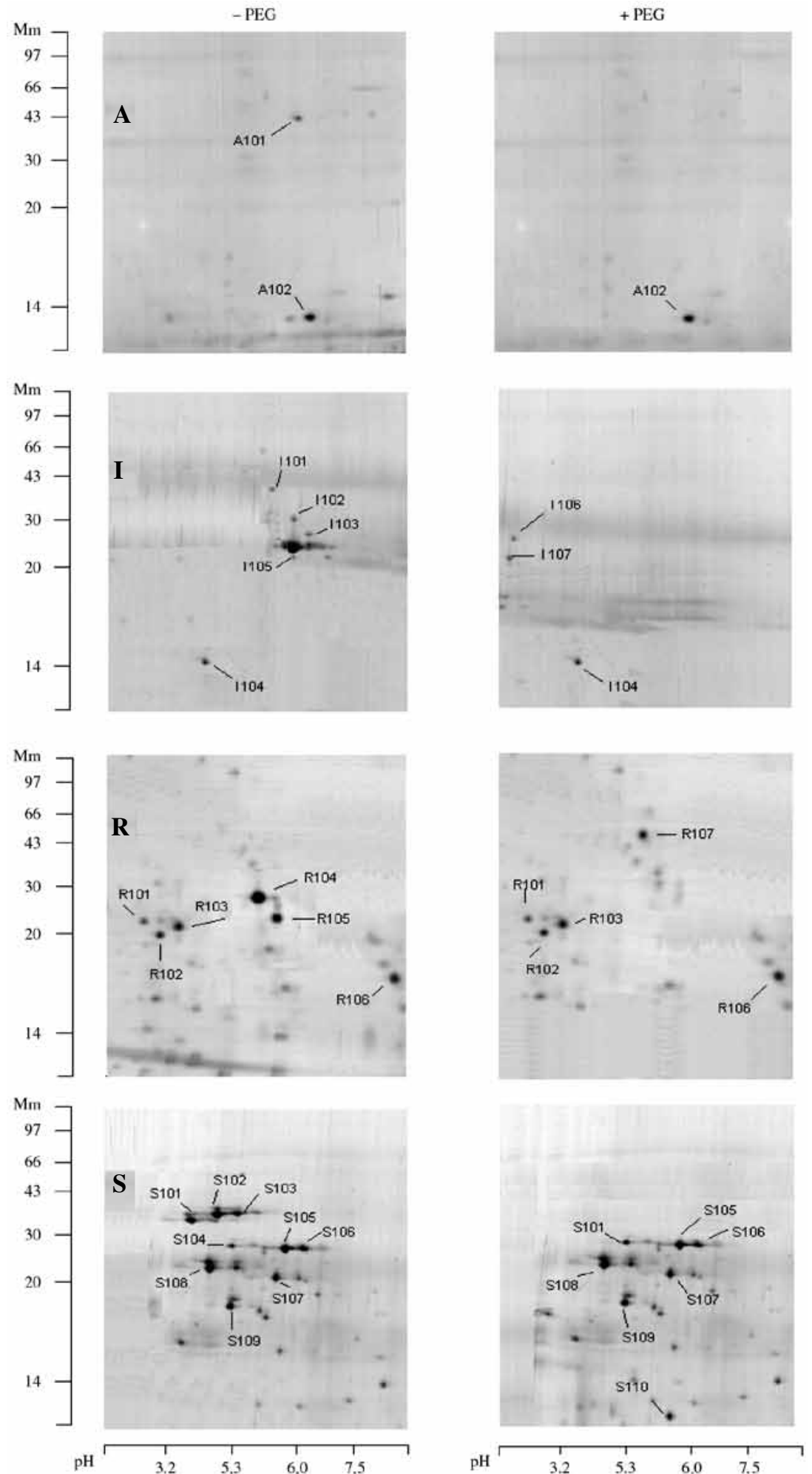

Figura 6. Análisis de expresión de proteínas en electroforesis bidimensional (2D) en poliacrilamida, coloreado con Coomassie blue de cuatro cultivares de cebolla. A: 'Americana', I: 'Ica', R: 'Ram', S: 'Sivan'. 
masa molecular, podrían tratarse de isoformas, pues difieren apenas en su punto isoléctrico (pI), evidenciando una microheterogeneidad molecular a través de posibles modificaciones postraduccionales, que podrían asociarse a una serie diversa de mecanismos en su función biológica, es decir, unas estarían cumpliendo un papel estructural y otras con mecanismos de detoxificación relacionados con la presencia de radicales libres. En 'Ica' y 'Sivan' con-PEG se muestra la expresión de peroxidasas que actúan sobre la neutralización de los radicales libres. En 'Ica' se expresó la ascorbato peroxidasa y la superóxido dismutasa y 'Sivan' respondió no expresando cuatro peroxidasas (Figura 7, Cuadro 1), pero mantuvo las enzimas ascorbato peroxidasa y la superóxido dismutasa, además de otra enzima que no fue detectada en el cultivar 'Ica' como es la geranilgeranil reductasa que estaría relacionada con la inhibición de la síntesis de giberelinas (Pell y Steffen, 1991). En 'Ram', sin capacidad para aclimatarse, desaparece la ascorbato peroxidasa, pero se expresa otra enzima, la catalasa, que posee actividad sobre radicales libres. Contrariamente, en 'Americana', de pobre crecimiento, se observó actividad peroxidasa sin-PEG pero con-PEG no expresó la enzima peroxidasa, indicando al parecer no ser afectada por el déficit hídrico moderado dado su pobre crecimiento, o que la vía implicada en la eliminación de radicales libres sería no enzimática. Se ha reportado que la exposición de las plantas a situaciones de estrés de baja temperatura y al déficit hídrico producen la formación de radicales libres, en estas condiciones la actividad de enzimas como superóxido dismutasa, catalasa, ascorbato peroxidasa y peroxidasa y la presencia de antioxidantes (ácido ascórbico, ácido dehidroascórbico y glutationa) permiten la neutralización de estos agentes tóxicos (Pell y Steffen, 1991). Muchas plantas que son resistentes al déficit hídrico muestran elevada presencia de antioxidantes como el tocoferol y ácido ascórbico, así como una elevada actividad de la superóxido dismutasa, ascorbato peroxidasa y catalasa (Pell y Steffen, 1991). En plantas de trigo expuestas a un severo déficit hídrico se incrementó la actividad superóxido dismutasa y catalasa con la consecuente disminución de la peroxidación de los lípidos de membrana (Navari-Izzo et al., 1993). En frijol la actividad superóxido dismutasa (SOD), catalasa, ascorbato peroxidasa y peroxidasa fue baja en especies sensibles (Turkan et al., 2005). La sobreexpresión de la SOD en la alfalfa después del déficit hídrico permitió un menor daño al ser expuesta a déficit hídrico más severo (McKersie et al., 1996). En girasol distintos niveles de déficit hídrico produjeron una disminución progresiva del contenido de proteína, antioxidantes e incremento de la actividad ascorbato peroxidasa (Sgherri y Navari-Izzo, 1995) y árboles siempre verdes expuestos a estrés presentaron actividad peroxidasa (Grace y Logan, 1996). De acuerdo a los reportes mencionados, se deduce que la tolerancia al estrés hídrico de 'Ica' y 'Sivan' estaría mediada por la presencia de las enzimas superóxido dismutasa $\mathrm{y}$ ascorbato peroxidasa, que no se presentaron en los cultivares sensibles 'Americana' y 'Ram', y en esta especie al parecer la ruta detoxificante sería la señalada por la reacción de Mehler, en la cual la superóxido dismutasa es una enzima clave (Bray et al., 2000). Asimismo, la presencia de syntaxina relacionada con el tráfico intracelular (Asada y Shibaoka, 1994) se mantuvo en 'Sivan', pero en 'Ica', con aclimatamiento, ésta desapareció. Por tanto, debido a que no se ha encontrado información sobre su relación con el estrés hídrico, es un estudio que debe considerarse. En 'Americana' la proteína NAP1, de múltiple función celular (Dong et al., 2005), permaneció luego del tratamiento con-PEG; al respecto no se ha encontrado información sobre esta proteína estructural y su relación con el déficit hídrico, abriendo posibilidades de nuevos estudios.

\section{Conclusiones}

El propósito del presente trabajo fue determinar la respuesta al déficit hídrico en cuatro cultivares de Allium cepa L. en cuanto a su sobrevivencia, cambios fisiológicos y moleculares, y su relación con la capacidad de tolerancia. De estos cultivares investigados, 'Ica' y 'Sivan', resultaron ser tolerantes al déficit hídrico, porque presentaron una mayor capacidad para aclimatarse al ser sometidas al déficit hídrico con PEG-8000 (10\% p/v), mientras el genotipo 'Ram' resultó ser el más sensible por no presentar capacidad para aclimatarse. El cultivar 'Americana', que no presentó capacidad para aclimatarse, mostró tolerancia intermedia al déficit hídrico. Las respuestas fisiológica y molecular fueron concordantes con respecto al incremento de solutos compatibles y la presencia de enzimas antioxidantes en los cultivares 'Ica' y 'Sivan', que son capaces de aclimatarse. 

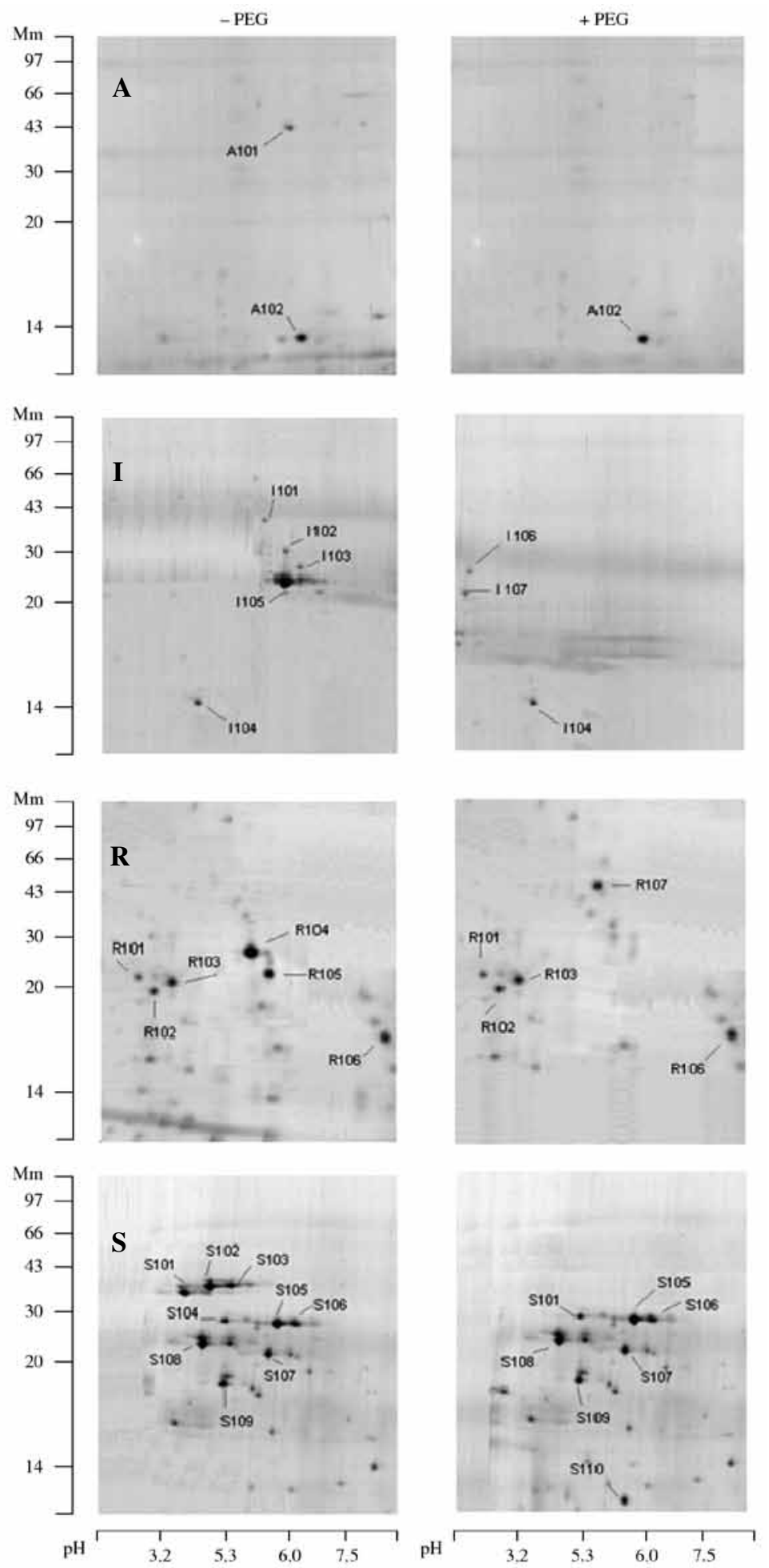

Figura 7. Análisis de expresión de proteínas en electroforesis bidimensional (2D) en poliacrilamida, coloreado con Coomassie blue, de callos de cuatro cultivares de Allium cepa L. después de 24 horas de exposición a un déficit hídrico moderado. A: 'Americana', I: 'Ica', R: 'Ram', S: 'Sivan'. 
Cuadro 1. Proteínas identificadas según la base de datos http://ca.expasy.org/tools/\#proteome en el análisis de imagen de los spots en geles bidimensionales elaborados a partir de los extractos de callos de cuatro cultivares de Allium cepa, después de 24 horas de aclimatación con PEG-8000 (10\% p/v).

\begin{tabular}{lrlll}
\hline Spot & Mm $(\mathrm{Da})$ & $\mathrm{pI}$ & \multicolumn{1}{c}{ Producto (SIN-PEG) } & \multicolumn{1}{c}{ Producto (CON-PEG) } \\
\hline A101 & $\mathbf{3 8 . 1 0 7 , 1 6}$ & $\mathbf{6 , 0}$ & Peroxidasa & \\
A102 & $\mathbf{1 2 . 2 3 6 , 1 7}$ & $\mathbf{6 , 2}$ & Probable proteína NAP1 & Probable proteína NAP1 \\
$\mathrm{I} 101$ & $38.109,45$ & 5,3 & Peroxidasa & \\
$\mathrm{I} 102$ & $27.415,65$ & 5,9 & Ascorbato peroxidasa & \\
$\mathrm{I} 103$ & $26.634,85$ & 7,2 & Superóxido dismutasa & \\
$\mathrm{I} 104$ & $14.265,65$ & 5,6 & Proteína PIR & Proteína PIR \\
$\mathrm{I} 105$ & $15.685,21$ & 4,2 & Syntaxin of plants [Fragment] & Ascorbato peroxidasa \\
$\mathrm{I} 106$ & $27.416,29$ & 2,5 & & Superóxido dismutasa \\
I107 & $26.289,54$ & 2,6 & & Geranylgeranyl reductase \\
R101 & $\mathbf{2 2 . 6 5 8 , 1 2}$ & $\mathbf{3 , 2}$ & Geranylgeranyl reductase & Flagellin B2 [Precursor] \\
R102 & $\mathbf{2 1 . 5 6 4 , 4 5}$ & $\mathbf{3 , 2}$ & Flagellin B2 [Precursor] & Putative syntaxin of plants 52 \\
R103 & $\mathbf{2 1 . 7 8 4 , 6 4}$ & $\mathbf{4 , 1}$ & Putative syntaxin of plants 52 & \\
R104 & $\mathbf{2 7 . 4 1 6 , 6 5}$ & $\mathbf{5 , 9}$ & Ascorbato peroxidasa & \\
R105 & $\mathbf{2 2 . 4 5 6 , 6 4}$ & $\mathbf{5 , 9}$ & Geranylgeranyl reductase & Syntaxin of plants [Fragment] \\
R106 & $\mathbf{1 6 . 8 9 2 , 8 4}$ & $\mathbf{7 , 8}$ & Syntaxin of plants [Fragment] & Catalasa \\
R107 & $\mathbf{5 6 . 4 6 3 , 4 5}$ & $\mathbf{6 , 3}$ & & Peroxidasa \\
S101 & $38.107,68$ & 3,9 & Peroxidasa & \\
S102 & $38.106,64$ & 4,9 & Peroxidasa & \\
S103 & $38.107,78$ & 5,1 & Peroxidasa & \\
S104 & $27.416,89$ & 5,4 & Ascorbato peroxidasa & \\
S105 & $27.417,64$ & 5,9 & Ascorbato peroxidasa & Ascorbato peroxidasa \\
S106 & $27.416,16$ & 6,3 & Ascorbato peroxidasa & Geranylgeranyl reductase \\
S107 & $22.459,32$ & 5,8 & Geranylgeranyl reductase & Superóxido dismutasa \\
S108 & $26.638,94$ & 4,5 & Superóxido dismutasa & Syntaxin of plants [Fragment] \\
S109 & $17.891,56$ & 5,0 & Syntaxin of plants [Fragment] & Putative syntaxin of plants 31 \\
S110 & $6.456,56$ & 5,5 & & \\
\hline & & & & \\
\end{tabular}

\section{Agradecimientos}

Agradecemos a la Empresa Comercializadora de Semillas SEMIAGRO (Arequipa, Perú) por haber proporcionado gentilmente las semillas de los cultivares estudiados. Asimismo, el reconocimiento a la bióloga Yésica Justo Godoy y a la bachiller en Cs. Claudia Arévalo Nieto, por su valiosa contribución durante el trabajo en laboratorio.

\section{Literatura citada}

Asada, T. y Shibaoka, H.

1994 Isolation of polypeptides with microtubule-translocating activity from phagmoplasts of tobacco BY-2 cells. Journal Cell Science 107: 2249-2257.

Bhaskaran, S.; Smith, R.; Newton, R.

1985 Physiological changes in cultured sorghum cells in response to induced water stress. Plant Physiology 79: 266-269.

Boyer, J.S.

1982 Plant Productivity and environment. Science 218: 443-448.

Bray, E.; Bailey-Serres, J.; Weretilnyk, E.

2000 Responses to Abiotic Stresses. In: Biochemistry \& Molecular Biology of Plants. B. Buchanan; W. Gruissem; R. Jones, Eds. American Society of Plant Physiologists, USA.

Claussen, W.

2005 Proline as a measure of stress in tomato plants. Plant Science 168: 241-248.
Dong, A.; Liu, Z.; Zhu, Y.; Yu, F.; Li, Z.; Cao, K.; Shen, W.H. 2005 Interacting proteins and differences in nuclear transport reveal specific functions for the NAP1 family proteins in plants. Plant Physiology 138: 1446-1456.

Dunstan, D.; Short, K.

1977 Improved growth of tissue cultures of the onion, Allium cepa. Plant Physiology 41: 70-72.

Grace, S.; Logan, B.

1996 Acclimation of foliar antioxidant systems to growth irradiance in three broad-leaved evergreen species. Plant Physiology 112: 1631-1640.

Handa, S.; Handa, A.; Hasegawa, P.; Bressan, R.

1986 Proline accumulation and the adaptation of cultured plant cells to water stress. Plant Physiology 80: 938-945.

Hasegawa, P.; Bressan, R.; Handa, S.; Handa A.

1984 Cellular mechanisms of tolerance to water stress. Hort Science 19 (3): 371-377. 
Ho, T.; Sachs, M.

1989 Environmental control of gene expression and stress protein in plants. In: Plants under stress, Ed. Jones, H., T.J. Flowers y M.B. Jones, Society for Experimental Biology, Seminar Series 39, pp. 157-180.

Kusaka, M.; García, A.; Fujimura, T.

2005. The maintenance of growth and turgor in peral Mollet (Pennisetum glaucum [L.] Leeke) cultivars with different root structures and osmo-regulation under drought stress. Plant Science 168: 1-14.

$\mathrm{Li}, \mathrm{Ch}$.

1969 Introducción a la estadística experimental. Omega. España, pp. 487-491

Li, Y.; Sorefan, K.; Hemmann, G.; Bevan, M.

2004. Arabidopsis NAP and PIR regulate Actin-Based Cell morphogenesis and multiple developmental processes. Plant Physiology 136:3616-3627.

McKersie, B.; Bowley, S.; Harjanto, E.; Leprince, O. 1996 Water-deficit tolerance and field performance of transgenic alfalfa overexpressing superoxide dismutase. Plant Physiology 111: 1177-1181.

Ministerio de Agricultura

2002 Modernización de la agricultura peruana: la visión regional en debate, $1^{\text {a }}$ ed. Incagro. Perú.

Navari-Izzo, F.; Milone, M.; Quartacci, M.; Pinzino, C. 1993 Metabolic changes in wheat plants subjected to a water - deficit stress programme. Plant Science 92: 151-157.

Pell, E.; Steffen, K.

1991 Active oxygen/oxidative stress and plant metabolism. American Society of Plant Physiologists. USA, p. 286.

Sgherri, C.; Navari-Izzo, F.

1995 Sunflower seedlings subjected to increasing water deficit stress: oxidative stresse and defence mechanisms. Physiology Plantarum 93: 25-30.

Singh, N.; Bracker, Ch.; Hasegawa, P.; Handa, A. 1987 Characterization of osmotin. Plant Physiology 85: 529-536.
Shen, Q.; Wang, J.

2006 Engineering for drought tolerance in horticultural and ornamental plants: Lessons from the studies with model plants. Journal Crop Improvement 17: 121-153.

Steubing, L.; Godoy, R.; Alberdi, M.

2002 Factores bióticos, vegetación. En: Métodos de ecología vegetal. Ed. Universitaria, Universidad Austral de Chile, pp. 159-322.

Tal, M.

1983 Selection for stress tolerance. In: Handbook of Plant Cell Culture. Vol 1. Macmillan Publishing Company New York. 830 p.

Towill, L.; Mazur, P.

1975 Studies on the reduction of 2,3,5-triphenyl tetrazolim chloride as a viability assay for plant tissue cultures. Canadian Journal of Botany 53: 1097-1102.

Tschaplinski, T.; Gebre, G.; Dahl, J.; Roberts, G.; Tuskan, G. 1995 Growth and solute adjustment of calli of Populus clones cultured on nutrient medium containing polyethylene glycol. Canadian Journal Forest Research 25: 1425-1433.

Türkan, I.; Bor, M.; Özdemir, F.; Koca, H.

2005 Differential responses of lipid peroxidation and antioxidants in the leaves of drought tolerant $P$. acutifolius Gray and drought sensitive $P$. vulgaris $\mathrm{L}$. subjected to polytethylene glycol mediated water stress. Plant Science 168: 223-231.

Whalley, W.R.; Lipiec, J.; Finch - Savage, W.E.; Cope, R.E., Clark, L.J.; Rowse, H.R.

2001 Water stress can induce quiescence in newly - germinated onion (Allium cepa L.) seedlings. Journal of Experimental Botany 52 (358): 1129-1133.

Westermeier, R.

2005 Electrophoresis in Practice: A guide to methods and applications of DNA and protein separations. $426 \mathrm{p}$. 
